\title{
Modification to the Barber and Keane's method of illustrating fungi
}

\author{
Almeida DAC ${ }^{1}$ and Gusmão LFP ${ }^{1}$ \\ ${ }^{1}$ Universidade Estadual de Feira de Santana, Av. Transnordestina, S/N - Novo Horizonte, 44036-900. Feira de \\ Santana, BA, Brazil.
}

Almeida DAC, Gusmão LFP 2015 - Modification to the Barber and Keane's method of illustrating fungi. Mycosphere 6(5), 630-633, Doi 10.5943/mycosphere/6/5/12

\begin{abstract}
Although less common nowadays, line drawing still is useful to represent morphological characters, in many cases better than digital photographic images. In this paper we describe two modifications that can be applied to the Barber \& Keane (2007) method, which combine computer hardware and software to make line drawings of fungi.
\end{abstract}

Key words - line drawing - mycology - fungi

\section{Introduction}

Drawings have been extensively used by mycologists since seventeenth century (Hook 1665) to illustrate fungal structures, being an important and widely used method for almost 300 years. There are many examples of wonderful line drawings of hyphomycetes and ascomycetes (Berlese 1900; Nag Raj 1993). In the last few decades, however, the rise and technological improvement of digital cameras has discouraged many mycologists from using line drawings in their publications. Other possible reasons are the draftsman skill necessary to make line drawings and the long time required to stipple, as many hundreds of small dots may be necessary to represent pigmentation. Line drawings are still helpful since they can present details that sometimes are unclear in photographic plates and also improve the observation skill of the taxonomist (Barber \& Keane 2007). To stimulate mycologists to use line drawings in their works, Barber \& Keane (2007) described a new method to produce a digital illustration of microfungi using computer hardware and software. Here we describe a modification of their method that makes it easier and cheaper and facilitates the production of excellent illustrations of fungi, even for those without artistic ability.

\section{Materials and Methods}

\section{Barber \& Keane's technique modified}

The Barber \& Keane (2007) method can be divided into four main steps: manual drawing, digitalization, vectorization and pigmentation. The first step of the Barber \& Keane's method does not differ from traditional technique, as both require the use of a drawing tube or camera lucida attached to a compound microscope. Thus both techniques also require minimal draftsman skill to complete the drawing by tracing over the viewed image onto a sheet of paper. At the second and third steps, the Barber \& Keane's method differs from traditional technique as it stipulates that the manual drawing should be scanned and vectorized using an appropriate software such as 
Macromedia FreeHand (www.macromedia.com), Adobe Illustrator (www.adobe.com) or Corel Draw (www.corel.com).

The first modification we propose is to replace the first and second steps of the Barber \& Keane's method for just one step: take a picture using a digital camera or images capture systems. In our proposed modification, the vectorized drawing is made directly on the digital picture using any of the software mentioned above. The technique to vectorize is the same as described by Barber $\&$ Keane (2007).

The second modification we suggest is on the fourth step of the Barber \& Keane's method, i.e. how the pigmentation is applied. This step is very important as it saves a significant amount of time that would be otherwise necessary to stipple by hand. Barber \& Keane (2007) proposed the use of a Series 3 Screen Filter (Andromeda Software Inc., www.andromeda.com) available as a plug-in for Adobe Photoshop. However this plug-in is not freely available. Instead of that the Series 3 Screen Filter, we suggest using another filter, "Mezzotint", which already is available on Adobe Photoshop and gives a similar effect. The modified technique are described below and the steps shown in Fig. 1.

With the drawing opened in the Photoshop, the "Magic Wand" tool is used to select the area within the outer cell walls. The "Mezzotint" filter is then used to fill the structure with small dots. To vary the degree of pigmentation, the "Brush" tool is used with "dissolve" mode selected. To darken or brighten any region of the structure, the black or white color must be selected, respectively, before using the "Brush" tool. The size, opacity and flow of the brush can be manipulated to vary the effect as desired. Finally, the file should be saved in an uncompressed format (such as .tiff). Two examples of complete line drawing are shown in Figures 2 and 3. We used microfungi species as example because are our expertise, but the technique can be used for all fungi.
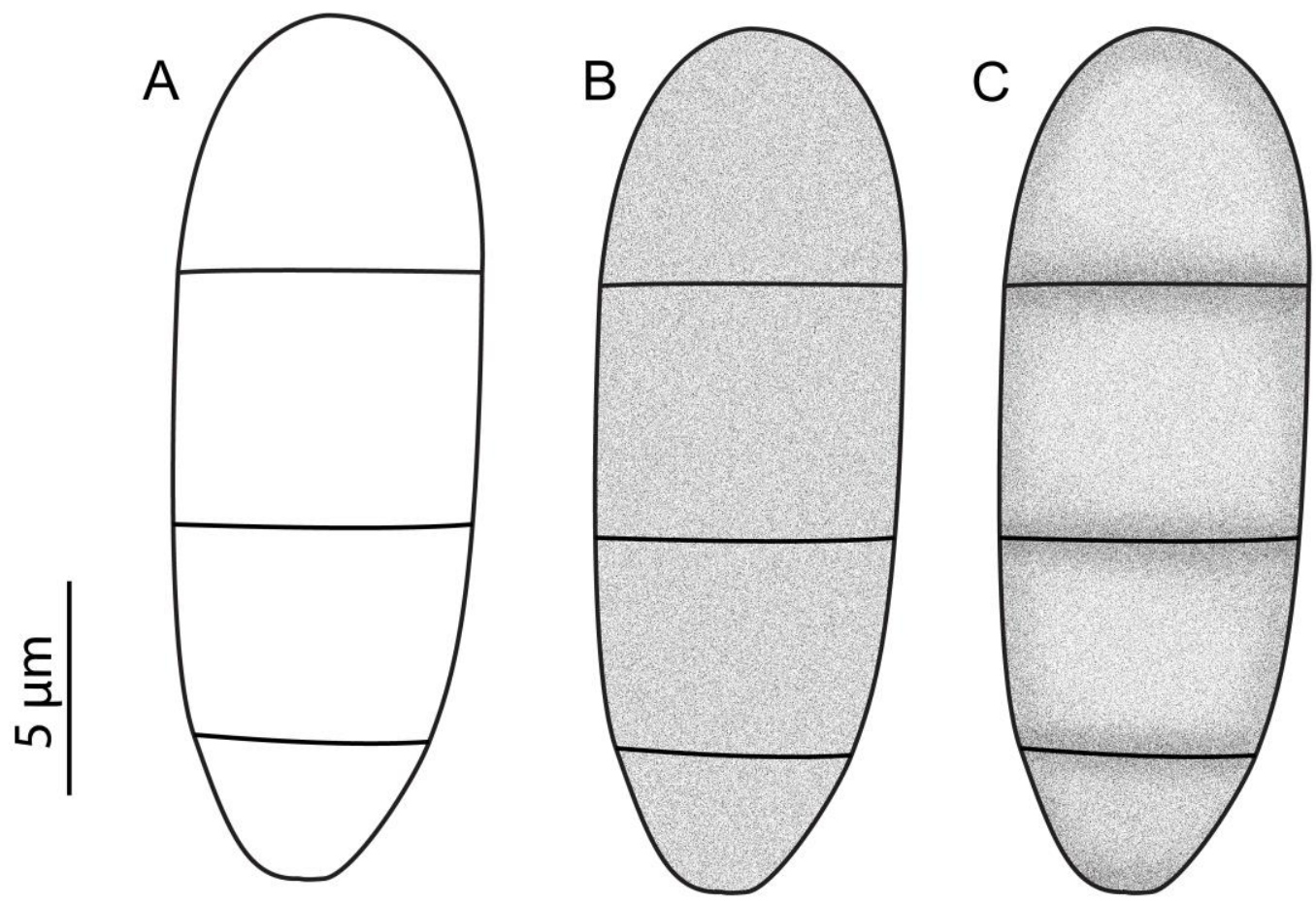

Fig. 1 - Line drawing of the conidia of Phaeoisaria triseptata Hol.-Jech., showing the individual steps of drawing. A. Final tracing as imported in Adobe Photoshop. B. Conidia after the "Mezzotint" filter has been applied. C. Final image after the "Brush" tool has been used. 


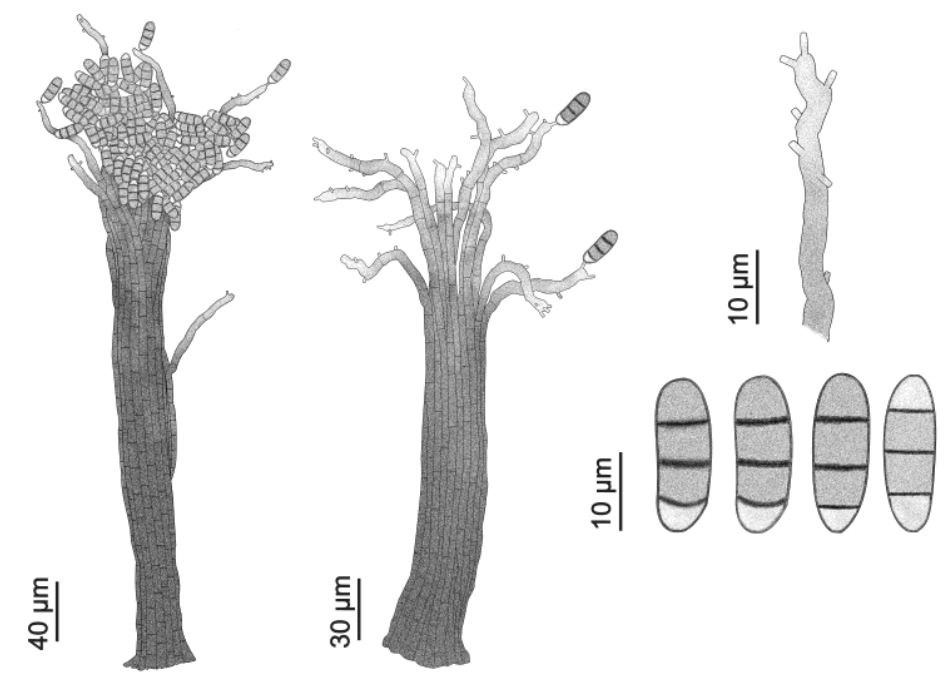

Fig. 2 - Line drawing of Phaeoisaria triseptata, made using the Barber \& Keane (2007) method with the modifications described on this paper.

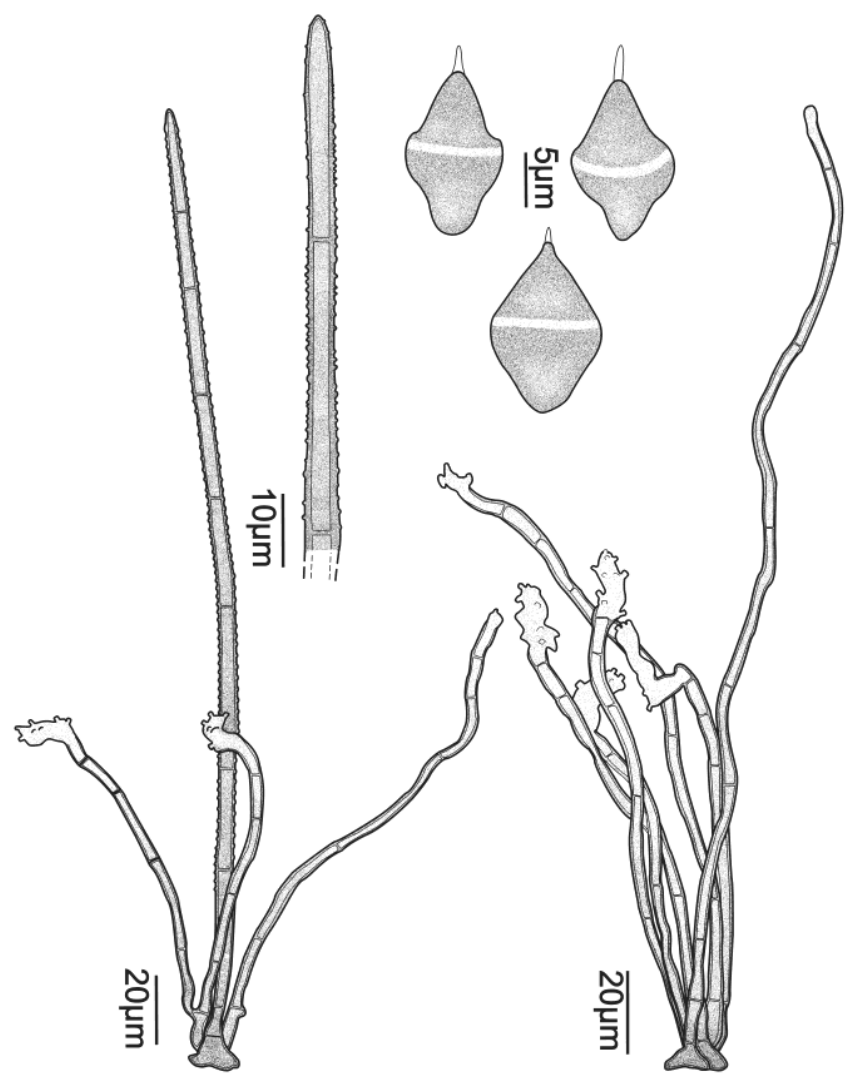

Fig. 3 - Line drawing of Beltrania magnoliae M. Morelet \& Vivant, made using the Barber \& Keane (2007) method with the modifications described on this paper. 


\section{Discussion}

The two modifications described in this work can be used as an easier and faster alternative to the Barber \& Keane (2007) method for digital illustration of fungi, as it does not require the use of a drawing tube or camera lucida, nor does it require the installation of the Series 3 Screen Filter. Thus, this method allows even mycologists without any draftsman skill can make composite line drawing of microstructures of fungi and invertebrates.

The method, with the modifications described here, has been used to illustrate new species and new records of microfungi from the Brazilian semi-arid region (Almeida et al. 2012; Cruz 2012; Almeida et al. 2013; Almeida et al. 2014; Almeida \& Gusmão 2014; Fiuza et al. 2014). The drawings published in two of these works, Almeida \& Gusmão (2014) and Fiuza et al. (2014) were chosen to illustrate the cover of two volumes of Mycotaxon, 129 and 127, respectively.

\section{Acknowledgements}

The authors thank Dr. Vince Hustad (University of Illinois at Urbana-Champaign, USA) for critically reviewing the manuscript. The first author also thanks the Brazilian Federal Agency for Support and Evaluation of Graduate Education (CAPES - proc. 071/2012) for the scholarship.

\section{References}

Almeida DAC, Barbosa FR, Gusmão LFP. 2012 - Alguns fungos conidiais aquáticos-facultativos do bioma Caatinga. Acta botanica brasílica 26, 924-932. doi:http://dx.doi.org/10.1590/S0102-33062012000400021

Almeida DAC, Cruz ACR, Marques MFO, Gusmão LFP. 2013 - Conidial fungi from the semi-arid Caatinga biome of Brazil. New and interesting Zanclospora species. Mycosphere 4 (4), 684-692. doi:http://dx.doi.org/10.5943/mycosphere/4/4/4

Almeida DAC, Miller AN, Gusmão LFP. 2014 - New species and combinations of conidial fungi from the semi-arid Caatinga biome of Brazil. Nova Hedwigia 98, 431-447. doi:10.1127/0029-5035/2013/0162

Almeida DACd, Gusmão LFP. 2014 - Ypsilomyces, a new thallic genus of conidial fungi from the semi-arid Caatinga biome of Brazil. Mycotaxon 129 (1), 181-186. doi:http://dx.doi.org/10.5248/129.181

Barber PA, Keane PJ. 2007 - A novel method of illustrating microfungi. Fungal Diversity 27 (1), $1-10$.

Berlese AN. 1900 - Icones Fungorum. Vol. 3. Sphaeriaceae: Allantosporae p. p. Patavii.

Cruz ACR. 2012 - Revisão do grupo Beltrania (Xylariales - Ascomycota). Universidade Estadual de Feira de Santana, Feira de Satana

Fiuza PO, Gusmão LFP, Cruz ACRd, Castañeda-Ruiz RF. 2014 - Conidial fungi from the semiarid Caatinga biome of Brazil: a new species of Pseudoacrodictys. Mycotaxon 127 (1), 33-37. doi:http://dx.doi.org/10.5248/127.33

Hook R. 1665 - Micrographia; or some Physiological Descriptions of Minute bodies made by Magnifying Glasses, with Observations and Inquiries thereupon. Thirty-eight plates, folio. London, vol Dover facsimile of the first edition. Dover Publishing Co, New York

Nag Raj T. 1993 - Coelomycetous anamorphs with appendage-bearing conidia. Mycologue Publications, Waterloo, Canada 